\title{
PERSPECTIVE: AgriCUltURAl AERIAL APPLICATION WITH UNMANNED AIRCRAFT SYSTEMS: CURRENT REGULATORY FRAMEWORK AND ANALYSIS OF OPERATORS IN THE UNITED STATES
}

\author{
Roberto Rodriguez ${ }^{1, *}$ \\ ${ }^{1}$ USDA Animal and Plant Health Inspection Service (APHIS) Plant Protection and Quarantine (PPQ) \\ Science and Technology (S\&T) Mission Laboratory, Edinburg, Texas, USA. \\ * Correspondence: Roberto.RodriguezIII@usda.gov.
}

\section{HighLIGHTS}

- The FAA has used two exemptions (17261 and 18009) as precedents for approval of numerous agricultural operations for unmanned aircraft systems (UAS).

- While many operators have received exemptions, a significant portion have not received an agricultural aircraft operator certificate (AAOC), despite the need for both to operate UAS in agricultural operations.

- Operators who have both an exemption and an AAOC tend to be clustered in geographic areas, with many states without a single such operator.

\begin{abstract}
Unmanned aircraft systems (UAS) have seen rapid growth in many industries in the U.S. since the introduction of small UAS regulations (14 CFR § 107). However, adoption of UAS for agricultural aerial application has been limited. Two landmark regulatory exemptions by the Federal Aviation Administration (FAA) have laid the foundation for commercial agricultural aerial application with UAS. Since the initial introduction of these exemptions, the pace of new exemptions for agricultural aerial application with UAS has remained steady. By the end of 2019, 64 operators had received exemptions in which the FAA cited one of the two landmark exemptions as a precedent. This study analyzed these exemptions to determine geographic distribution, aircraft manufacturer, number of employees, and time to operator certification. Results indicate that less than half of operators who received an exemption from the FAA became certified for aerial application. Additionally, certified operators were not evenly distributed throughout the U.S. despite the broader distribution of exemption holders. Two UAS manufacturers dominated the market, with over $80 \%$ of exemptions requesting UAS from one or both manufacturers. While regulatory hurdles for agricultural aerial application with UAS have been substantially reduced through the introduction of standardized exemptions, this has not resulted in the anticipated influx of certified operators. There are additional impediments preventing operator certification, including technological limitations of currently available UAS, which need to be addressed to improve the rate of UAS integration into agricultural aerial application.
\end{abstract}

Keywords. Chemical applications, Drone, Precision agriculture, UAS, UAV, Unmanned aerial vehicle, Unmanned aircraft systems.

A doption of unmanned aircraft systems (UAS) into civil sectors has proceeded at a rapid pace. According to the Federal Aviation Administration (FAA) aerospace forecast for FY 2019-2039 (FAA, 2019), by the end of 2018, more than 277,000 nonmodel aircraft (non-recreational) UAS were registered in the U.S. Precision agriculture has been estimated as a significant sector of the overall UAS market in multiple economic

Submitted for review on 28 September 2020 as manuscript number MS 14331; approved for publication as a Perspective and as part of the UAVs in Agriculture Collection by the Machinery Systems Community of ASABE on 16 June 2021.

Mention of company or trade names is for description only and does not imply endorsement by the USDA. The USDA is an equal opportunity provider and employer. evaluations (Jenkins and Vasigh, 2013; Vascik and Jung, 2016). However, several studies have shown that regulatory restrictions have impeded the adoption of UAS technology in the agricultural market (Freeman and Freeland, 2014; Vascik and Jung, 2016).

The FAA has made substantial strides in advancing agricultural aerial application operations in the past decade. Agricultural aerial application operations are defined in this review, in the context of 14 CFR $\S 137$ (CFR, 2019d), as the operation of an aircraft for the purpose of dispensing a substance directly affecting agriculture, horticulture, or forest preservation, including pest control, plant nourishment, and soil treatment. In the FAA Reauthorization Act of 2018 (FAA, 2018a), the U.S. Congress specifically directed the FAA to provide a report to address the requirements for UAS 
to engage in aerial spraying of chemicals for agricultural purposes. Progress has primarily been made through the exemption process created by the FAA Modernization and Reform Act of 2012 (FAA, 2012). This process was repealed by PL $115-254 \S 347$ and replaced with the Special Authority for Certain Unmanned Systems (USC, 2018). This review presents the foundational exemptions that have established the current regulatory framework for agricultural aerial application operations with UAS and analyzes the current body of exemptions that have been issued in this framework.

\section{Precedent-SetTing EXeMPtions Exemption 11448}

Exemption 11448 was issued to Yamaha Motors Corporation on May 5, 2015, for aerial application with the Yamaha RMAX Type II G (Yamaha, 2015). This was the first UAS approved for aerial application under 14 CFR $\S 91$ (CFR, $2019 b$ ). This exemption laid the foundation for all UAS aerial application operations by establishing which regulations in 14 CFR $§ 137$ (CFR, 2019d) could be waived for UAS. Largely, these were regulations regarding occupant safety, pilot certificate limitations, aircraft certification, maintenance, and operational requirements, which were incompatible with UAS. This exemption predated the promulgation of 14 CFR $\S$ 107 (CFR, 2019c), limiting remote pilots to those with an airmen certificate issued under 14 CFR $\S 61$ (CFR, 2019a).

\section{Exemption 17261}

Exemption 17261 was issued to DroneSeed on March 17, 2017, for aerial application with the DS-8 and DS-9 (DroneSeed, 2017). This exemption was the first issued for agricultural aerial application after 14 CFR $\S 107$ (CFR, 2019c) established a new airmen certificate for remote pilots and operating rules for small UAS, i.e., UAS weighing less than $55 \mathrm{lb}(25 \mathrm{~kg})$. The introduction of the remote pilot certificate removed the need for relief from $14 \mathrm{CFR} \S 61$ and 91 but maintained the relief granted for 14 CFR $\S 137$ (CFR, 2019d). Exemption 17261 also added an exemption to the prohibition against the carriage of hazardous materials
(14 CFR $\S 107.36$ ) in order for the UAS to administer agricultural chemicals such as economic poisons, i.e., pesticides, and fertilizers.

\section{Exemption 18009}

Exemption 18009 was issued to Powers Flight Group on October 11, 2018, for aerial application with the HSE-UAV AG-V6A+ v2 (Powers Flight Group, 2018). This exemption set a new precedent by making use of a UAS that exceeded the $55 \mathrm{lb}$ limit for small UAS established in 14 CFR $\S 107$, requiring waivers from $14 \mathrm{CFR} \S 61$ and 91, while allowing the remote pilot in command to have a remote pilot certificate issued under 14 CFR $\S 107$ rather than requiring an airmen certificate issued under 14 CFR $\S 61$. This increased the operational payload capacity of available UAS for aerial applications while eliminating the previous barrier to entry that required remote pilots to have a private pilot certificate. This was previously identified as a major limitation for adoption of UAS in aerial application (Vascik and Jung, 2016).

A major limitation of Exemption 18009 was the need for an Air Traffic Organization (ATO) issued Certificate of Waiver or Authorization (COA) for each operation. This was streamlined in November 2019 when a blanket COA was issued for "any operator with a valid 49 USC $\$ 4807$ Grant of Exemption" (Agdrone Applications, 2019). This blanket COA permits the operation of UAS in accordance with the operators' 49 USC $\S 44807$ Grant of Exemption in class G airspace at or below 400 feet above ground level (AGL) in the National Airspace System (NAS). This blanket COA is similar in most respects to the second blanket COA for operations in accordance with a PL 112-95 $§ 333$ Grant of Exemption issued in March 2016, which laid the foundation for the introduction of 14 CFR $\S 107$ (FAA, 2016).

\section{REgULATIONS WAIVED}

Exemptions 11448, 17261, and 18009 standardized the set of exemptions that are waived by the FAA to conduct aerial application with UAS, as shown in table 1. Exemptions 17261 and 18009 drew on the regulations waived by

Table 1. List of regulations waived by Exemptions 11448, 17261, and 18009. Empty cells (-) indicate regulations that do not apply to the operations under consideration.

\begin{tabular}{|c|c|c|c|c|}
\hline $14 \mathrm{CFR}$ & Description & 11448 & 17261 & 18009 \\
\hline 61.3(a)(1)(i) & Requiring a pilot certificate under $\S 61.19$ & - & - & $\mathrm{X}$ \\
\hline 61.23(a) and (c) & Requiring medical certificates & $\mathrm{X}$ & - & - \\
\hline $61.101(\mathrm{e})(4)$ and (5) & Recreational pilot limitations & $\mathrm{X}$ & - & - \\
\hline 61.113(a) & Private pilot limitations & $\mathrm{X}$ & - & - \\
\hline $91.7(a)$ & Requiring a civil airworthiness certificate & $\mathrm{X}$ & - & $\mathrm{X}$ \\
\hline $91.119(\mathrm{c})$ & Minimum safe altitude over other than congested areas & $\mathrm{X}$ & - & $\mathrm{X}$ \\
\hline 91.121 & Altimeter settings & $\mathrm{X}$ & - & $\mathrm{X}$ \\
\hline 91.151 & Fuel requirements for flight in Visual Flight Rules & $\mathrm{X}$ & - & $\mathrm{X}$ \\
\hline $91.405(\mathrm{a})$ & Maintenance inspection requirements & $\mathrm{X}$ & - & $\mathrm{X}$ \\
\hline $91.407(\mathrm{a})(1)$ & Maintenance approval requirements & $\mathrm{X}$ & - & $\mathrm{X}$ \\
\hline $91.409(\mathrm{a})(1)$ and (2) & Maintenance inspection requirements (annual and airworthiness) & $\mathrm{X}$ & - & $\mathrm{X}$ \\
\hline 91.417(a) and (b) & Maintenance records requirements & $\mathrm{X}$ & - & $\mathrm{X}$ \\
\hline 107.36 & Carriage of hazardous material & - & $\mathrm{X}$ & - \\
\hline $137.19(\mathrm{c})$ & Commercial pilot requirement & $\mathrm{X}$ & $\mathrm{X}$ & $\mathrm{X}$ \\
\hline $137.19(\mathrm{~d})$ & Aircraft airworthiness certificate requirement & $\mathrm{X}$ & $\mathrm{X}$ & $\mathrm{X}$ \\
\hline 137.19(e)(2)(ii), (iii), and (v) & Skill requirements: (ii) approaches, (iii) flare-outs, and (v) pullups and turnarounds & $\mathrm{X}$ & $\mathrm{X}$ & $\mathrm{X}$ \\
\hline $137.31(\mathrm{a})$ & Aircraft airworthiness requirements & $\mathrm{X}$ & $\mathrm{X}$ & $\mathrm{X}$ \\
\hline $137.31(\mathrm{~b})$ & Shoulder harness requirement & $\mathrm{X}$ & $\mathrm{X}$ & $\mathrm{X}$ \\
\hline $137.33(\mathrm{a})$ & Requirement to carry operator certificate & $\mathrm{X}$ & $\mathrm{X}$ & $\mathrm{X}$ \\
\hline $137.33(\mathrm{~b})$ & Requirement to keep airworthiness certificates available & - & $\mathrm{X}$ & $\mathrm{X}$ \\
\hline $137.41(\mathrm{c})$ & Pilot in Command commercial pilot requirement & - & $\mathrm{X}$ & $\mathrm{X}$ \\
\hline 137.42 & Fastening of safety belt and shoulder harness & $\mathrm{X}$ & $\mathrm{X}$ & $\mathrm{X}$ \\
\hline
\end{tabular}


Exemption 14488 and incorporated changes resulting from the promulgation of 14 CFR $\S 107$. These two exemptions have split aerial application by UAS into two categories based on weight. Operators seeking to use UAS with a maximum takeoff weight (MTOW) below $55 \mathrm{lb}$ will cite Exemption 17261 and will operate under 14 CFR § 107. Alternatively, operators seeking to use UAS with a MTOW above $55 \mathrm{lb}$ will cite Exemption 18009 and will operate under 14 CFR § 91; however, the pilot only needs a remote pilot certificate issued under 14 CFR $\S 107$.

In addition to FAA regulations, aerial applications by UAS are also subject to U.S. Environmental Protection Agency (EPA) regulations. The EPA requires that applications of restricted-use pesticides are performed by licensed applicators (40 CFR § 152.170; CFR, 1995). Only applications of restricted-use pesticides require a license, and general-use pesticides may be applied without a pesticide applicator license, unless a state or local government places additional restrictions. If a UAS operator will be applying restricted-use pesticides, the operator will specifically need an aerial pesticide applicator license. Pesticide applicator licenses are conferred by relevant state agencies.

\section{MATERIALS AND MeTHODS}

This review analyzed the exemptions in the public register (accessed through www.regulations.gov) issued under PL 112-95 § 333 and 49 USC $\S 44807$ containing either Exemption 17261 or Exemption 18009 as an enclosure with the FAA's decision letter granting the exemption. The exemption number, applicant name, date granted, enclosed exemption, state, use of legal counsel, and UAS manufacturer and model for each exemption holder were recorded. This review further analyzed the FAA's database of aircraft operators (accessed through www.aviationdb.com). The database was initially queried for 14 CFR $\S 137$ (Part 137) operators with a UAS listed as one of the aircraft operated. For all exemption holders not found in the initial query, the database was further queried by each operator name. The certificate number, operator type (commercial, government, academic, or individual), state, date issued, and number of employees for

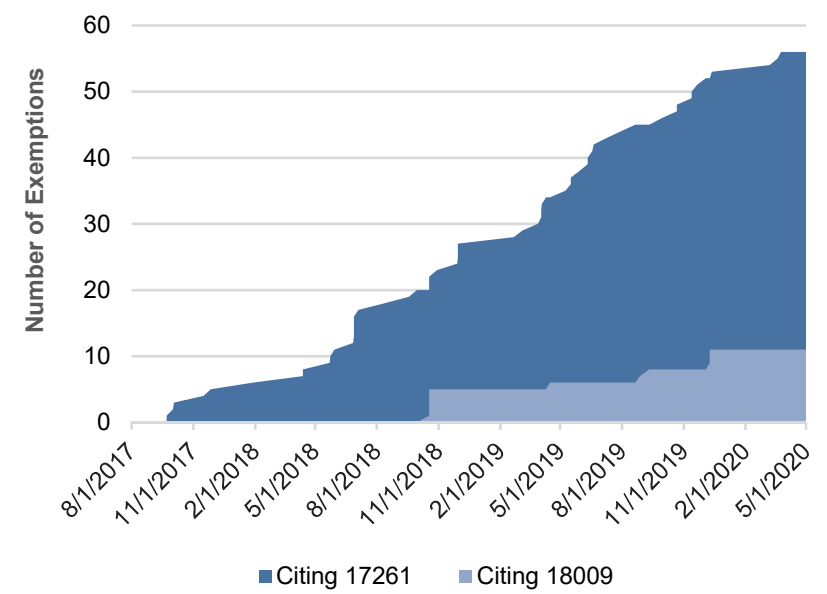

(a) each agricultural aircraft operator certificate (AAOC) were recorded. Operator types are defined as commercial (an entity that operates for compensation or hire), government (the operator is the government of the U.S., a state, the District of Colombia, or a territory or possession of the U.S., or a political subdivision of one of these governments), academic (the operator is an educational institution), or individual (the operator is a single individual). The date on which certificate was issued was compared with the date on which operator's exemption was granted to determine the time required for the operator certification process.

\section{RESULTS AND DISCUSSION EXEMPTIONS}

As of June 1, 2020, a total of 67 exemptions had been granted in which the FAA enclosed either Exemption 17261 or Exemption 18009 (fig. 1). There has been a gradual increase since both exemptions were initially granted. Over $80 \%$ of the exemption holders are commercial entities, with a small number of government, academic, and individual entities making up the remainder.

The UAS used under these exemptions are largely sourced from three companies (fig. 2a): SZ DJI Technology Co. (DJI), Homeland Surveillance and Electronics (HSE), and Beijing TT Aviation Technology Co. (TTA). Over 80\% of exemption holders requested to operate UAS manufactured by DJI and/or HSE. The dominance of DJI reflects the U.S. UAS domestic market as a whole (Skylogic Research, 2017). It should be noted that while the mentioned UAS are those listed in the decision letter, additional UAS may be added without requesting an amendment to the operator's exemption.

Only $32 \%$ of exemption holders had outside legal counsel submit the exemption request on their behalf (fig. 2b). However, looking exclusively at the eleven exemption holders citing Exemption 18009, six (55\%) of the exemption holders made use of legal counsel. Both cases are substantially higher than the $4.5 \%$ of waiver applications under 14 CFR § 107.200 , indicating a significantly higher reliance on external legal expertise (DAC, 2019).

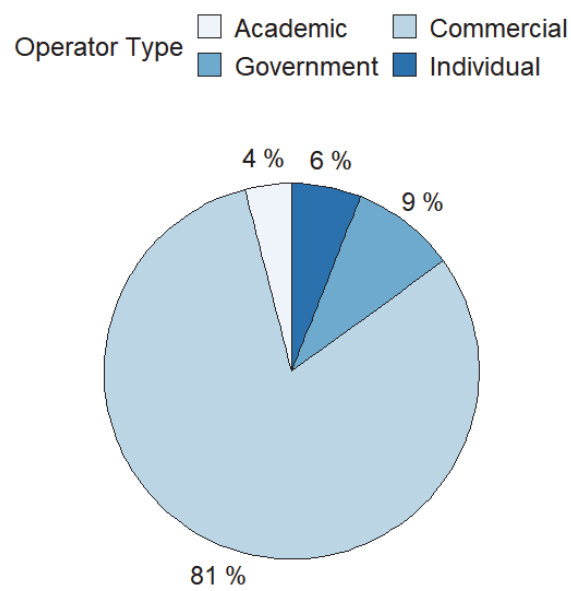

(b)

Figure 1. (a) Number of exemptions in which the FAA enclosed Exemption 17261 or Exemption 18009 over time, and (b) breakdown of exemption holders by type: commercial, government, academic, or individual $(n=67)$. 


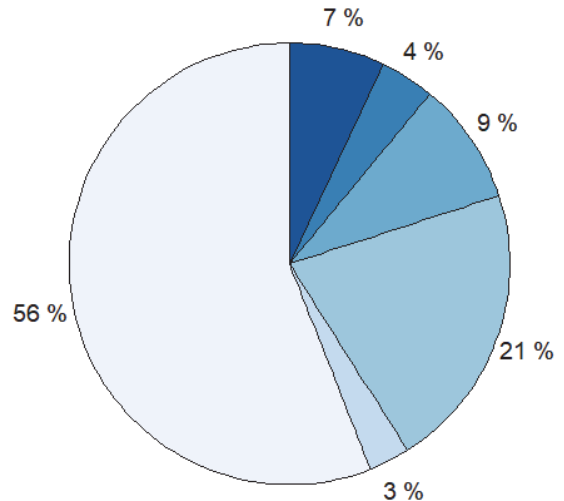

(a)

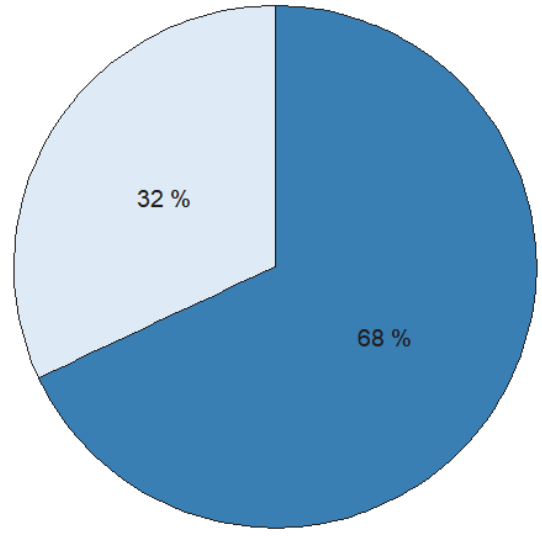

(b)

Figure 2. (a) Percentage of exemptions granted (as of May 1, 2020) by UAS manufacturer and (b) submissions by legal counsel ( $n=67)$.

\section{Agricultural Aircraft Operator Certificate}

Following the grant of an exemption from the relevant regulations, a UAS operator must then secure an AAOC through their local Flight Standards District Office. Guidance for the certification and surveillance of Part 137 operators with UAS was not added until August 2017 (FAA, 2017a). The certification process is described in FAA Order 8900.1 Volume 2 Chapter 8 Section 1 (FAA, 2018b). A limiting step in the certification process is that the chief supervisory pilot must pass a knowledge and skill tests as described in FAA Order 8900.1 Volume 5 Chapter 11 Section 1 (FAA, 2017b). The elements of the skill test that are exempted for remote pilots have been the same since Exemption 11448. The Letter of Authorization issued with the AAOC includes the list of all aircraft, including UAS, with which the operator may conduct Part 137 operations.

Results from the aviation database search indicate that only 30 Part 137 operators have UAS listed on their certificates. Of these 30 certificates, 27 were issued after Exemption 17261 was granted, with the majority issued after May 2018 (fig. 3). Of the 67 exemption holders citing Exemption
17261 or Exemption 18009, four had an AAOC prior to their exemption being granted that listed manned aircraft.

The average time between an exemption being granted and the operator being certified for Part 137 operations was 152 days. Forty percent of the operators received their AAOC within 120 days of receiving their grant of exemption (fig. 4). The minimum was 18 days, and the maximum was 390 days. Overlaying the number of AAOCs with corresponding exemptions and the total number of exemptions, figure 4 shows a strong trend of exemptions granted without an AAOC being issued.

\section{GEOGRAPHIC DISTRIBUTION OF OPERATORS}

While exemption holders are distributed across the U.S. (fig. 5), there are currently 17 states without an exemption holder. Of the 33 states that have an exemption holder, the majority (16) have a single exemption holder. However, the geographic distribution of Part 137 operators with certificates for operating UAS shows isolated pockets of operators. Currently, 33 states do not have a certified operator, and only nine states have more than one certified operator.

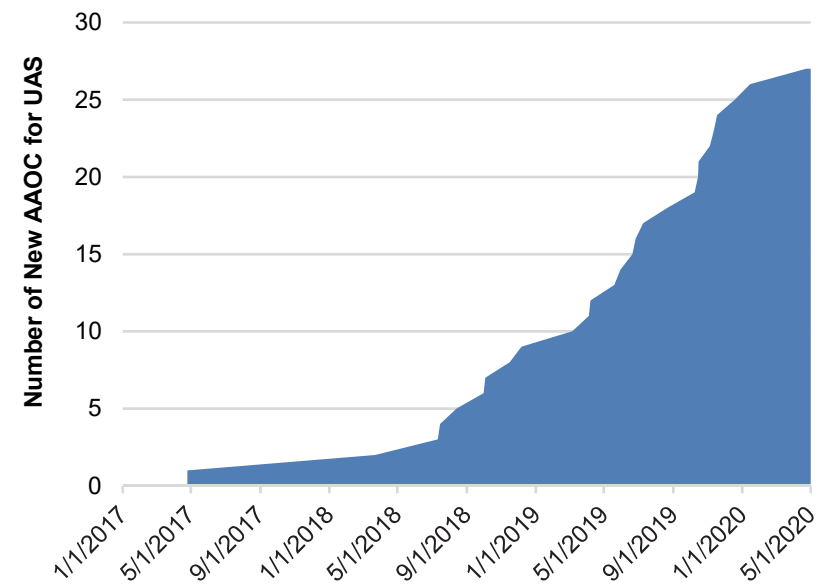

(a)
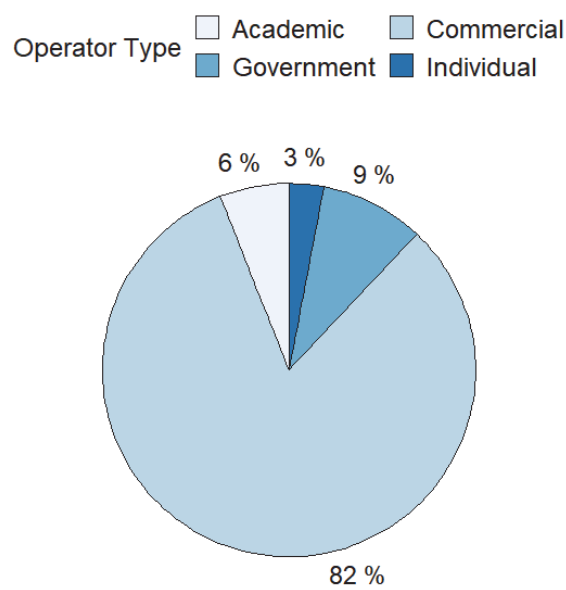

(b)

Figure 3. (a) New agricultural aircraft operator certificates (AAOCs) issued for UAS following Exemption 17261 and (b) breakdown of AAOC holders by type: commercial, government, or individual $(n=33)$. 


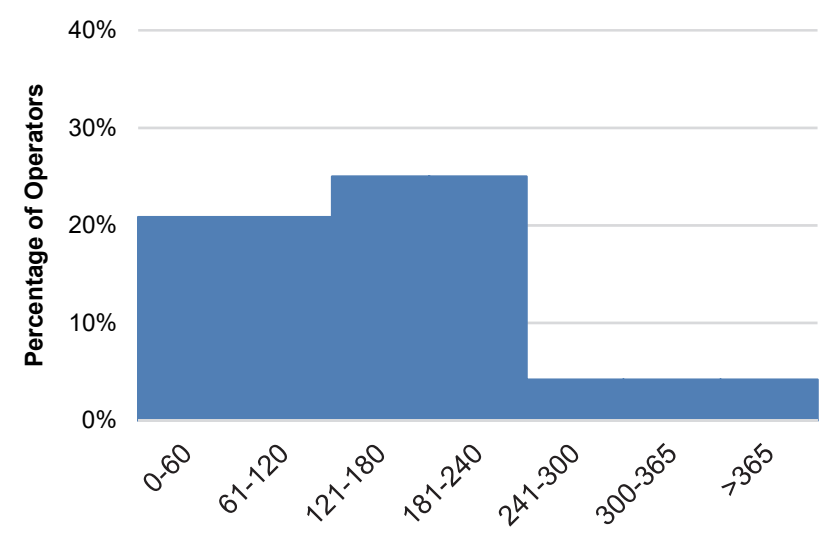

Days Between Grant of Exemption and AAOC Issue

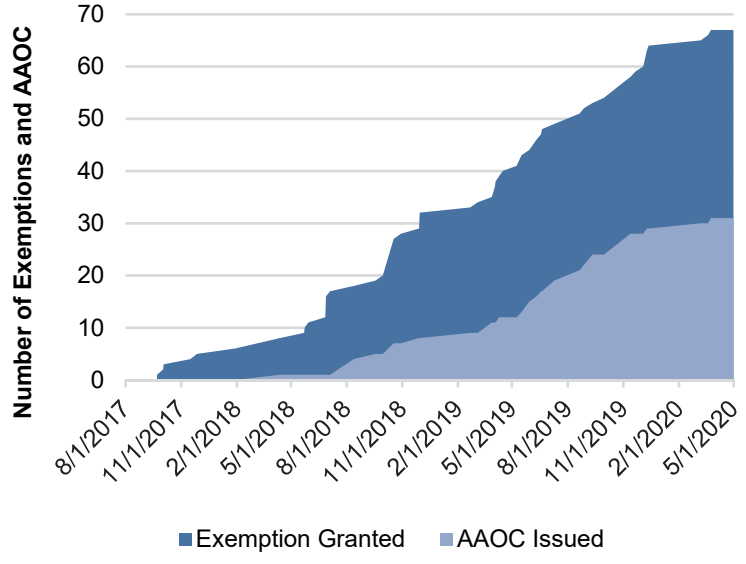

(b)

Figure 4. (a) Days between grant of exemption for agricultural aerial application with UAS and issue of a Part 137 operator certificate ( $n=24)$, and (b) number of exemptions for agricultural aerial application with UAS and AAOC issued to UAS operators.

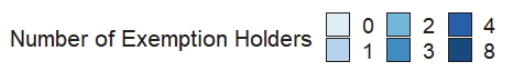

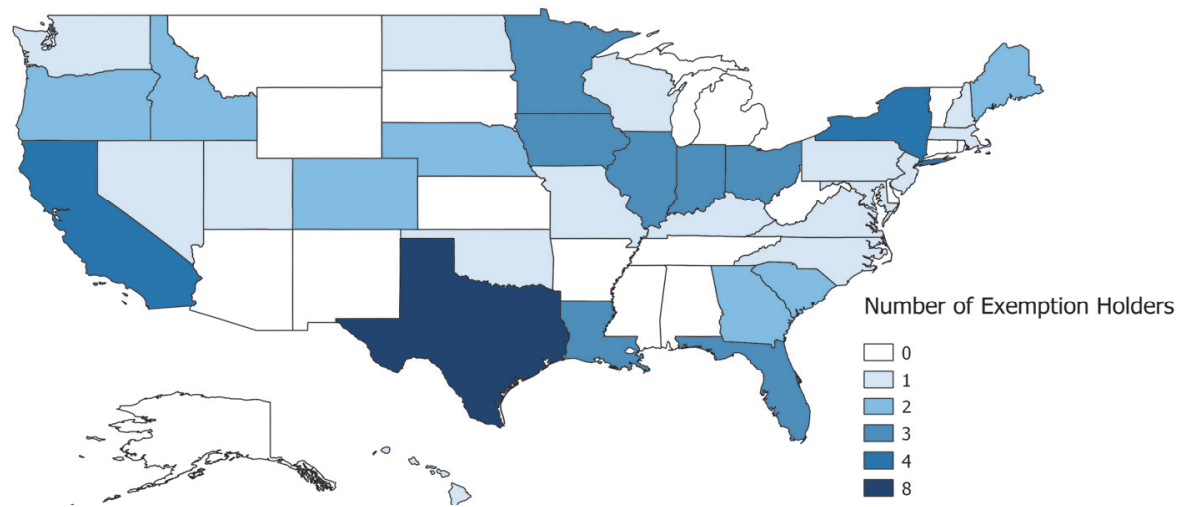

(a)

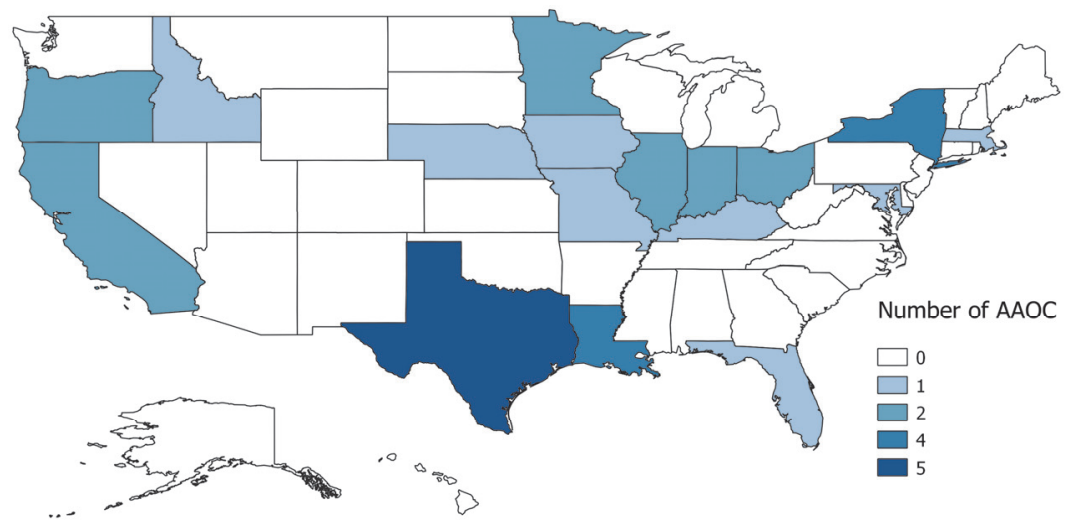

(b)

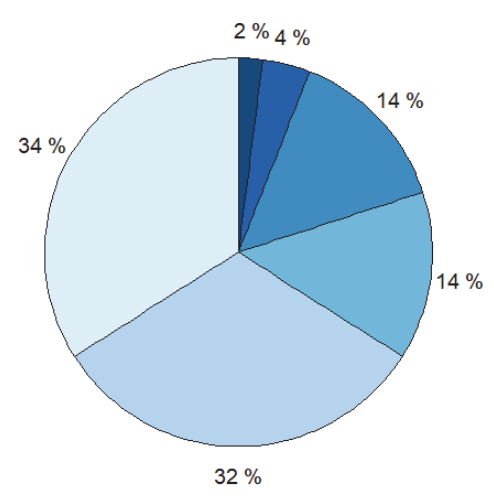

Number of AAOC $\square 0 \square 1 \square 2$

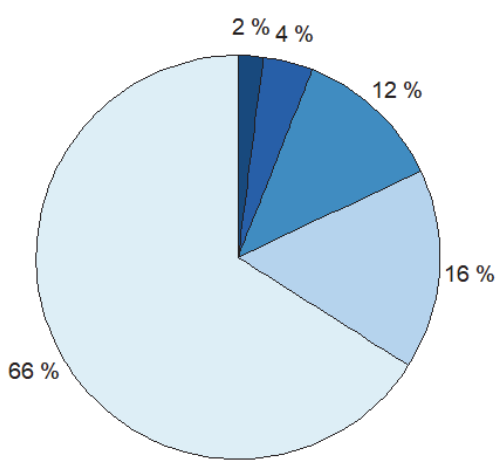

Figure 5. Distributions of (a) exemption holders and (b) AAOCs in the U.S.

There are only 80 remote pilots listed for those Part 137 certificates explicitly for UAS. Given the limited payload capacity of approved UAS, the small number of employees per operator indicates that the majority of these businesses are relatively small (fig. 6). Despite the substantial reduction in regulatory hurdles, based on the number, size, and distribution of Part 137 operators using UAS, agricultural aerial application continues to be a minute portion of the overall UAS market. This suggests that additional factors beyond perceived regulatory burdens are limiting the growth of this industry. 
Number of Employees $\square$\begin{tabular}{l}
1 \\
\hdashline
\end{tabular} $\begin{aligned} & 3 \\
& 2\end{aligned} \begin{aligned} & 3 \\
& 5\end{aligned} \square>6$

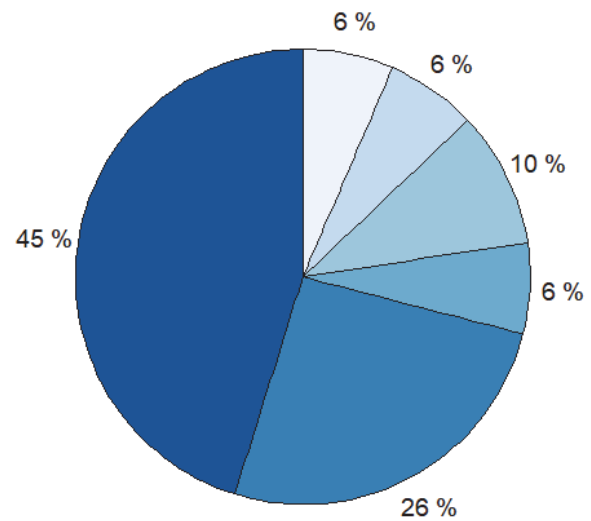

Figure 6. Number of remote pilot employees per Part 137 operator.

\section{LiMitaTions OF CURRENTLY APPROVED UAS}

The majority of UAS that have been approved for agricultural aerial application are designed and manufactured in China. The average farm size in China is only 0.67 ha (Eastwood et al., 2010). This area can be reasonably covered by the listed UAS. However, the average farm size in the U.S. is 178 ha (USDA, 2019). Consequently, these UAS do not meet the needs of the larger agricultural operations in the U.S. Previous investigations by NASA on the certification of UAS for aerial application in the U.S. focused on UAS with MTOW of approximately $1000 \mathrm{lb}(450 \mathrm{~kg})$ (Hayhurst et al., 2015; Maddalon et al., 2016). Due to the aforementioned technological limitations, the available market for UAS in the U.S. remains small.

While Exemption 18009 laid the initial groundwork for UAS exceeding the $55 \mathrm{lb}$ limit for small UAS, the operation of civil UAS in excess of $100 \mathrm{lb}(45 \mathrm{~kg})$ is still in the very early stages of development. On April 20, 2019, the FAA issued special class airworthiness criteria for the Yamaha Fazer R, which has an MTOW of $244 \mathrm{lb}$ (110 kg) (Yamaha, 2019a). The issuing of a type certificate for the aircraft is a significant departure from previous civil UAS operations, which have requested relief from the requirement for an airworthiness certificate. On September 11, 2019, Yamaha received Exemption 18325, which authorized operation of the Yamaha Fazer R (Yamaha, 2019c). While Yamaha had initially requested that remote pilots be required to hold a minimum of a private pilot certificate (Yamaha, 2019b), the FAA's grant of exemption instead cited the conditions and limitations of Exemption 18009, requiring a remote pilot certificate with a small UAS rating (Yamaha, 2019c). The ability to use remote pilot certificates issued under 14 CFR $\S 107$ to operate these larger UAS would prevent the bottleneck of pilot certification under 14 CFR $\S 61$, which was a significant impediment to UAS integration prior to the introduction of 14 CFR $\S 107$.

\section{Conclusions}

While the operation of UAS for agricultural aerial application remains fairly limited, tremendous progress has been made in the last five years to standardize regulatory exemptions for these types of operations. FAA decisions citing Exemption 17261 or Exemption 18009 have substantially reduced the barriers for operators to enter this market space. Despite the reduction in regulatory barriers, the number, size, and distribution of operators continues to remain small. This suggests that factors beyond regulatory constraints are limiting the growth of this market. One limitation that was identified is the dependence on UAS that were designed for relatively small areas to meet the needs of the Chinese domestic market and that are poorly suited to meet the needs of U.S. agriculture. Regulations for UAS that are better suited to meet the needs of U.S. agriculture, i.e., UAS exceeding $100 \mathrm{lb}$, are still in the very early stages of development.

\section{REFERENCES}

CFR. (2019a). 14 CFR § 61: Title 14, Chapter I - U.S. Department of Transportation, Federal Aviation Administration, Volume 2, Part 61 - Certification: Pilots, flight instructors, and ground instructors. Washington, DC: U.S. Code of Federal Regulations.

CFR. (2019b). 14 CFR § 91: Title 14, Chapter I - U.S. Department of Transportation, Federal Aviation Administration, Volume 2, Part 91 - General Operating and Flight Rules. Washington, DC: U.S. Code of Federal Regulations.

CFR. (2019c). 14 CFR § 107: Title 14, Chapter I - U.S. Department of Transportation, Federal Aviation Administration, Volume 3, Part 107 - Small Unmanned Aircraft Systems. Washington, DC: U.S. Code of Federal Regulations.

CFR. (2019d). 14 CFR § 137: Title 14, Chapter I - U.S. Department of Transportation, Federal Aviation Administration, Volume 3, Part 137 - Agricultural Aircraft Operations. Washington, DC: U.S. Code of Federal Regulations.

CFR. (1995). 40 CFR $\S 152.170$ : Title 40, Chapter I Environmental Protection Agency, Volume 24, Part 152 Pesticide Registration and Classification Procedures. Washington, DC: U.S. Code of Federal Regulations.

USC. (2018). 49 USC § 44087: Title 49 -Transportation, Subtitle VII - Aviation Programs, Part A - Air Commerce and Safety, Chapter 448 - Unmanned Aircraft Systems, Section 44807 Special authority for certain unmanned aircraft systems. Washington, DC: U.S. Code.

Agdrone Applications. (2019). 49 USC 44807 Blanket COA Template - Final effective November 2019 [FAA Form 7711-1] In Doc. No. FAA-2019-0810. New Carlisle, OH: Agdrone Applications.

DAC. (2019). DAC member (public) information for the October 17, 2019 DAC meeting. Washington, DC: Federal Aviation Administration, Drone Advisory Committee.

DroneSeed. (2017). Grant of Exemption. In Doc. No. FAA-20169247. Seattle, WA: DroneSeed Company.

Eastwood, R., Lipton, M., \& Newell, A. (2010). Chapter 65 farm size. In Handbook of agricultural economics (Vol. 4, pp. 33233397). Amsterdam, Netherlands: Elsevier. https://doi.org/10.1016/S1574-0072(09)04065-1

FAA. (2012). FAA Modernization and Reform Act of 2012, congress.gov, P.L. No. 112-95 § 333. Washington, DC: Federal Aviation Administration. 
FAA. (2016). Blanket COA for any operator issued a valid section 333 Grant of Exemption [FAA Form 7711-1]. Washington, DC: Federal Aviation Administration. Retrieved from https://www.faa.gov/uas/advanced_operations/section_333/how to file a petition/media/Section-333-Blanket-400-COAEffective.pdf

FAA. (2017a). Advisory Circular 137-1B, Certification process for agricultural aircraft operators. Washington, DC: Federal Aviation Administration. Retrieved from https://www.faa.gov/documentLibrary/media/Advisory_Circular /AC_137-1B.pdf

FAA. (2017b). Order 8900.1 Volume 5 Airmen certification, Chapter 11 Administer a knowledge and skill test to an agricultural pilot, Section 1 Qualify a pilot in command. Washington, DC: Federal Aviation Administration. Retrieved from

https://fsims.faa.gov/PICDetail.aspx?docId=8900.1,Vol.5,Ch11, Sec 1

FAA. (2018a). FAA Reauthorization Act of 2018, congress.gov, P.L. No. 115-254 § 361. Washington, DC: Federal Aviation Administration.

FAA. (2018b). Order 8900.1 Volume 2 Air operator and air agency certification and application process, Chapter 8 Certification of a Part 137 operator, Section 1, The certification process of a Part 137 operator. Washington, DC: Federal Aviation Administration. Retrieved from https://fsims.faa.gov/PICDetail.aspx?docId=8900.1,Vol.2,Ch8,S ec1

FAA. (2019a). FAA aerospace forecast fiscal years 2019-2039. (TC19-0002). Washington, DC: Federal Aviation Administration. Retrieved from https://www.faa.gov/data_research/aviation/aerospace_forecasts/ media/FY2019-39_FAA_Aerospace_Forecast.pdf

Freeman, P. K., \& Freeland, R. S. (2014). Politics \& technology: U.S. polices restricting unmanned aerial systems in agriculture. Food Policy, 49, 302-311. https://doi.org/10.1016/j.foodpol.2014.09.008
Hayhurst, K. J., Maddalon, J. M., Neogi, N. A., Verstynen, H. A., Buelow, B., \& McCormick, G. F. (2015). Mock certification basis for an unmanned rotorcraft for precision agricultural spraying. Langley, VA: NASA Langley Research Center.

Jenkins, D., \& Vasigh, B. (2013). The economic impact of unmanned aircraft systems integration in the United States. Arlington, VA: Association for Unmanned Vehicle Systems International (AUVSI). Retrieved from https://www.auvsi.org/our-impact/economic-report

Maddalon, J. M., Hayhurst, K. J., Neogi, N. A., Verstynen, H. A., \& Clothier, R. A. (2016). Expanding the envelope of UAS certification: What it takes to type certify a UAS for precision agricultural spraying. Proc. AUVSI Xponential. Arlington, VA: Association for Unmanned Vehicle Systems International (AUVSI).

Powers Flight Group. (2018). Grant of exemption. In Doc. No. FAA-2018-0574. Bradenton, FL: Powers Flight Group.

Skylogic Research. (2018). 2018 Drone market sector report. Redwood City, CA: Skylogic Research.

USDA. (2019). 2017 Census of Agriculture. Washington, DC: USDA National Agricultural Statistics Service. Retrieved from www.nass.usda.gov/AgCensus

Vascik, P. D., \& Jung, J. (2016). Assessing the impact of operational constraints on the near-term unmanned aircraft system traffic management supported market. Proc. 16th AIAA Aviation Technology, Integration, and Operations Conf. https://doi.org/10.2514/6.2016-4373

Yamaha. (2015). Grant of exemption. In Doc. No. FAA-2014-0397. Cypress, CA: Yamaha Motor Corporation USA.

Yamaha. (2019a). Airworthiness criteria: Special class airworthiness criteria for the Yamaha Fazer R. In Doc. No. FAA-2018-0379. Cypress, CA: Yamaha Motor Corporation USA.

Yamaha. (2019b). Application for exemption. In Doc. No. FAA2019-0146. Cypress, CA: Yamaha Motor Corporation USA.

Yamaha. (2019c). Grant of exemption. In Doc. No. FAA-20190146. Cypress, CA: Yamaha Motor Corporation USA. 